\section{O ADOLESCENTE QUE COMETEU ABUSO SEXUAL EXTRAFAMILIAR: MOTIVAÇÃO E SOFRIMENTO}

\section{The Adolescent who Committed Extrafamilial Sexual Offense: Motivation and Suffering}

\author{
El Adolescente que Cometió Abuso Sexual Extrafamiliar: \\ Motivación y Sufrimiento
}

\section{L'adolescent qui a Commis l'abus Sexuel Extrafamilial: La Motivation et la Souffrance}

\section{Resumo}

Este artigo busca analisar os sentidos subjetivos que adolescentes que cometeram abuso sexual atribuem à violência cometida. Esta é uma realidade pouco conhecida e discutida no Brasil. O estudo evidencia aspectos da subjetividade de dois adolescentes a partir da análise de entrevistas clínicas. $\mathrm{O}$ estudo da subjetividade desses adolescentes permite conhecer sua realidade social, assim como conhecê-los em sua singularidade para que tenham acesso à atenção específica e não mais cometam abusos sexuais. Recorreu-se à Teoria da Subjetividade de González Rey como fundamentação teórica e ao seu método construtivo-interpretativo. Os resultados evidenciam que a violência configura-se um marco que limita o desenvolvimento desses adolescentes, seja por dimensões individuais ou sociais. Muitas são as contradições que constituem sua subjetividade: curiosidade e repressão da sexualidade; experimentação do ato sexual e arrependimento; relação submissa à mãe controladora e dominadora; desejo e culpa. Ressalta-se a importância do compromisso ético e social da psicologia diante desta realidade complexa. Não se trata apenas de promover o desenvolvimento psíquico saudável desses adolescentes, mas também de empreender o rompimento do ciclo de violência sexual e social.

Palavras-chave: adolescente; abuso sexual; violência extrafamiliar; subjetividade.

\begin{abstract}
This article seeks the subjective meanings that adolescent sexual offenders give to the violence committed. This issue is rarely known and discussed in Brazil. The study shows aspects of the subjectivity of two adolescents based on clinical psychological interviews analysis. The study of the subjectivity of these adolescents allows us to know the offenders' social reality and singularity, so they can have access to a specific care in order to stop sexual offenses. We used the Theory of Subjectivity of González Rey and his constructive and interpretative method. The results showed that the violence configures a landmark that limits the development of these adolescents in both, social and individual dimensions. There are many contradictions that constitute their subjectivity: curiosity and repression of their sexuality; sex experimentation and regret; submissive relationship with their controlling and overbearing mother; desire and guilt. We highlight the relevance of ethics and social commitment of the psychology in facing this complex situation. Our scope is not just to promote psychic healthy development, but also to undertake the interruption of sexual and social violence cycle.
\end{abstract}

Keywords: adolescent; sexual offense; extrafamilial violence; subjectivity.

\section{Resumen}

Este artigo busca los sentidos subjetivos que el adolescente que cometió abuso sexual atribuye a la violencia cometida. Esta es una realidad poco conocida y discutida en Brasil. El estudio evidenció aspectos de la subjetividad de dos adolescentes por medio del análisis de entrevistas clínicas. El estudio de la subjetividad de esos adolescentes permite conocer su realidad social, así como conocerlos en su singularidad para que tengan acceso al cuidado
Artigo Original

Florença Ávila de Oliveira

$\operatorname{Costa}^{(1)}$

Liana Fortunato Costa ${ }^{(2)}$ Maria Inês Gandolfo Conceição ${ }^{(3)}$

1) Psicóloga, Terapeuta Conjugal e Familiar, Mestre em Psicologia Clínica e Cultura pela Universidade de Brasília.

2) Psicóloga, Terapeuta Conjugal e Familiar, Psicodramatista. Doutora em Psicologia Clínica pela Universidade de São Paulo. Professora do Programa de PósGraduação em Psicologia Clínica e Cultura da Universidade de Brasília.

3) Psicóloga. Doutora em Psicologia Clínica pela Universidade de Brasília, Pós-doutora em Psicossociologia pela Universidade Fluminense e pela University of Toronto. Professora do Programa de PósGraduação em Psicologia Clínica e Cultura da UnB.
Recebido em: 18/03/2013 Revisado em: 08/04/2014 Aceito em: 18/06/2014 
especifico y no más cometan abusos sexuales. Se recorrió a la Teoría de la Subjetividad de González Rey como fundamentación teórica y a su metodología constructivo-interpretativa. Los resultados revelan que la violencia se configura un marco que limita el desarrollo de esos adolescentes, sea por dimensiones individuales o sociales. Muchas son las contradicciones que constituyen su subjetividad: curiosidad y represión de la sexualidad; experimentación y arrepentimiento; relación sumisa a la madre controladora y dominadora; deseo y culpa. Subrayamos la importancia del compromiso ético y social de la psicología ante esa realidad compleja. No se trata apenas de promover el desarrollo psíquico saludable de esos adolescentes, pero también de emprender del rompimiento del ciclo de violencia sexual y social.

Palabras clave: adolescente; abuso sexual; violencia extrafamiliar; Subjetividad.

\section{Résumé}

Cet article recherche les sens subjectifs que l'adolescent qui a commis des abus sexuels attribue sur les violences commises. L'étude met en évidence les aspects de la subjectivité de deux adolescents à partir de l'analyse des entrevues cliniques. C'est une réalité peu connue et discutée au Brésil. L'étude de la subjectivité des ces adolescents permet de connaître sa réalité sociale, ainsi comme de le connaître dans leur singularité afin qu'ils aient accès à des attention plus spécifiques et qu'il ne commette plus d'abus sexuels. Nous avons utilisé la Théorie de la Subjectivité, de González Rey, comme base théorique et sa méthodologie constructive interprétative. Les résultats ont montré que la violence limite le développement de ces adolescents, soit par les dimensions individuelles ou sociales. Nombreuses sont les contradictions qui constituent leur subjectivité: curiosité et répression de la sexualité; expérimentation et repentir; une relation de soumission à la mère contrôleur et dominatrice; désir et culpabilité. Nous soulignons l'importance de l'engagement éthique et social de la psychologie devant cette réalité complexe. Il ne s'agit pas seulement de promouvoir le développement de la bonne santé psychologique de ces adolescents, mais aussi de procéder à une rupture du cycle de violence sexuelle et sociale.

Mots-clés: adolescent; abus sexuels; violence extrafamiliale; subjectivité.

Este artigo trata de um recorte da pesquisa clínica intitulada "O adolescente que cometeu abuso sexual: estudo da subjetividade no contexto clínico", a qual busca apreender os sentidos subjetivos que o adolescente atribui à violência cometida. Este recorte evidencia aspectos da subjetividade de dois adolescentes em cumprimento de medida socioeducativa de Liberdade Assistida (LA), durante o primeiro atendimento psicológico clínico. Eles apresentam uma produção subjetiva anterior e posterior ao ato de abuso sexual. Assim, o presente trabalho levou à compreensão de suas motivações iniciais, que são constituídas socialmente, assim como constatou um sofrimento posterior a partir de uma realidade histórica e cultural estigmatizante. Portanto, o trabalho refere-se a sentidos subjetivos resultantes da motivação e do sofrimento de adolescentes que cometeram abuso sexual.

Essa realidade é pouco conhecida e discutida no cenário nacional, tendo em vista que existem poucos estudos e trabalhos sobre o tema publicados no Brasil. A maioria das publicações referentes ao adolescente que cometeu abuso sexual é internacional (Estados Unidos, Reino Unido, Canadá, Nova Zelândia e Austrália). Algumas exceções apresentam-se nesse quadro: Bianchini e De Antoni (2012); Costa, Junqueira, Ribeiro e Meneses (2011); Costa, Junqueira, Meneses, Stroher e Moura (2012); Costa, Junqueira, Meneses e Stroher (2013). Essas publicações abrangem o conhecimento sobre a caracterização do fenômeno em Porto Alegre, sobre a condição de desproteção do adolescente que cometeu ofensa sexual, e o enfoque nas relações familiares violentas desse adolescente.

Neste estudo busca-se refletir sobre a proteção em uma perspectiva dos direitos humanos de crianças e adolescentes (Machado, 2003) e da prevenção de novas reincidências de violência sexual em contextos complexos como são aqueles que constituem a realidade brasileira. Este texto apresenta conhecimento inédito e pretende ampliar a discussão ainda incipiente sobre esses adolescentes, em nosso país.

\section{Adolescentes que Cometeram Abuso Sexual}

O abuso sexual, como uma das manifestações de violência sexual, é toda situação em que crianças ou adolescentes são usados para gratificação sexual de pessoas mais velhas. É um ato imposto pela força física, pela ameaça ou pela sedução, com palavras ou com oferta de presentes, podendo ser intrafamiliar, extrafamiliar ou institucional (Santos, Neumann \& Ippolito, 2004). Nos casos de abusos sexuais, mais do que estabelecer o parentesco, é importante identificar o grau de autoridade do(a) autor(a) da violência sobre a vítima, pois evidencia a relação de poder e dominação estabelecida (Faleiros \& Faleiros, 2007).

As dimensões presentes no abuso sexual - tais como: seus atores, as polaridades que o constituem como vítima e algoz, seu contexto, a relação de poder, sexualidade e gênero, contemplam sua complexidade relacional, social, cultural e histórica. Assim sendo, o abuso sexual enquanto violência não é um ato isolado, mas um processo constituído por uma cultura de normas, valores, limites, papéis e tantos outros aspectos que constituem a subjetividade da violência expressa em uma sociedade adultocêntrica (Azevedo \& Guerra, 1989).

Diante dessa complexidade, pesquisas realizadas nas 
duas últimas décadas em países como Estados Unidos, Reino Unido, Austrália, Nova Zelândia e França (Chagnon, 2008, 2009; Oliver, 2007; Sanderson, 2005; Worling, Litteljohn \& Bookalam, 2010) têm apontado o crescente índice de abuso sexual cometido por adolescentes e que muitos dos autores adultos iniciaram os atos de violência sexual contra crianças na adolescência. No Brasil, a $1^{\text {a }}$ Vara da Infância e da Juventude do Distrito Federal apresenta anualmente o cadastramento e os dados estatísticos referentes a casos de violência sexual envolvendo crianças e adolescentes ali atendidos. Em 2011, 20\% dos autores de violência sexual contra crianças e adolescentes registrados tinham entre 12 e 17 anos.

Quanto aos dados do estado de Goiás, onde esta pesquisa foi realizada, não há registros formalizados de órgãos do governo ou da justiça referente ao adolescente que cometeu abuso sexual. Contudo, no ano de 2006, o Projeto Invertendo a Rota da pró-reitoria de extensão da Pontifícia Universidade Católica de Goiás identificou e atendeu dois adolescentes que cometeram abuso sexual contra criança. Já no ano de 2012, foram seis adolescentes identificados, encaminhados e atendidos, só na cidade de Goiânia. Segundo Sanderson (2005), é vital identificar os adolescentes abusadores, para que tenham acesso à atenção específica e assim evitar futuros abusos sexuais de crianças e/ou adolescentes e que fiquem condenados ao sistema prisional na vida adulta.

Ao se referir diretamente ao desenvolvimento do adolescente que cometeu abuso sexual, Chagnon (2009) afirmou que tais manifestações de violência sexual remetem a falhas educativas parentais, ausências afetivas, conflitos com autoridade ou contexto familiar permissivo. Já Penso, Conceição, Costa e Carreteiro (2012) definiram o ato de abuso sexual cometido pelo adolescente, como um pedido de socorro. $\mathrm{O}$ mesmo assim age para que seja dada atenção à sua condição de duplo pertencimento a diferentes papéis, ou seja, na ausência paterna, além de "filho" assume inconscientemente o papel de "marido" da mãe, o que gera sofrimento psíquico. Marcelli e Braconnier (1989) definiram acting out ou passagem ao ato como ações de caráter impulsivo que se opõem a ações de verbalização e reflexão, ou seja, um agir que expressa o conflito. Tal reflexão corrobora o que Chagnon (2008) afirmou sobre a dificuldade dos adolescentes que cometem abuso sexual de falar e refletir sobre seu ato, de se identificar com a vítima e com a sua dor.

Tais considerações são referentes a aspectos parentais, contextuais e subjetivos, privilegiando o fato de que os jovens estão em um processo contínuo de constituição psíquica. Portanto, a intervenção com adolescentes que cometeram abuso sexual torna-se primordial, tanto para a não reincidência quanto para a promoção da qualidade de vida e de seu desenvolvimento saudável. Nesse sentido, cabe acentuar a concepção social de proteção do adolescente com o reconhecimento político e legal da pessoa humana em condição peculiar de desenvolvimento e como sujeito de direito. O Estatuto da Criança e do Adolescente (Brasil, 1990) afirmou o valor de crianças e adolescentes como seres humanos, a necessidade de especial respeito e o reconhecimento de sua vulnerabilidade, o que os torna merecedores de proteção integral por parte da família, da sociedade e do Estado.

\section{A Teoria da Subjetividade}

A partir da perspectiva histórico-cultural, a subjetividade aparece para González Rey (2005b) como um macrossistema processual e contraditório que integra o pensamento do sujeito as suas emoções e as situações vividas por ele, as quais aparecem em uma multiplicidade de sentidos subjetivos, que se constituem e se desenvolvem constantemente em processos históricos e sociais. O sentido subjetivo que González Rey (2004) colocou no centro da definição de subjetividade foi influenciado pelo conceito de sentido de Vygotsky. A categoria dos sentidos subjetivos é definida como "um tipo de unidade auto-organizada da subjetividade que se caracteriza por uma integração de significados e processos simbólicos e de emoções" (González Rey, 2004, p. 17). Nessa categoria é evidenciada a centralidade das emoções, que representam um momento da qualidade dos relacionamentos e estão comprometidas com os processos de auto-organização da subjetividade.

Para González Rey (2004), o sujeito se constitui subjetivando a realidade na qual está inserido e suas ações objetivas são fontes de subjetivação. À vista disso, o sujeito é a pessoa viva, ativa, presente e pensante que se posiciona e produz sentidos subjetivos, expressando-se como sujeito na legitimidade de seu pensamento. Portanto, só é possível pensar o sujeito e sua subjetividade a partir das dimensões histórica, social, simbólica e emocional simultaneamente nos âmbitos coletivo e individual.

Nesse sentido, compreende-se a adolescência, também enquanto um fenômeno sócio-historicamente constituído. Ozella $(2002,2003)$ propôs o estudo da adolescência, a partir da psicologia sócio-histórica de Vygotsky, que aponta para o estudo dos fenômenos psicológicos enquanto resultado de um processo de constituição social do indivíduo. Essa constituição acontece por meio das relações sociais, em um processo interativo e dialético entre pensamento e linguagem (Vygotsky, 2005). 


\section{Método}

\section{Contexto}

A pesquisa foi realizada no contexto do Projeto "Invertendo a Rota: ações de proteção aos direitos de crianças e adolescentes em situação de exploração sexual". É um projeto de enfrentamento da violência sexual infantojuvenil em Goiás. Desenvolvido e coordenado pelo Centro de Estudos, Pesquisa e Extensão Aldeia Juvenil, vinculado à pró-reitoria de extensão da Pontifícia Universidade Católica de Goiás.

\section{Participantes}

Foram convidados e atendidos dois adolescentes. Ambos respondiam ao critério definido para a pesquisa, ou seja, eram adolescentes (Augusto e Daniel, nomes fictícios para a garantia do sigilo de suas identidades) de sexo masculino, que abusaram sexualmente de crianças e/ ou adolescentes e estavam inseridos no sistema judiciário em cumprimento de medida socioeducativa Liberdade Assistida (LA), encaminhados ao Projeto Invertendo a Rota pela DEPAI - Delegacia de Polícia de Apuração de Atos Infracionais. Tanto Augusto quanto Daniel vivem em contextos sociais empobrecidos, com renda média familiar de $\mathrm{R} \$ 276,70$, possuem baixa escolaridade e provém de famílias muito religiosas, o que favorece uma significativa repressão da sexualidade.

Augusto (17 anos) é o segundo de três filhos. Quando criança, não reagia e apanhava muito dos outros. $\mathrm{O}$ pai de Augusto trabalha como pedreiro, é um homem tímido. A mãe é aposentada devido a uma doença em seus ossos, e por tal motivo tem dificuldades de andar. A relação de Augusto com sua mãe é de admiração e submissão. Ela o trata como seu filho preferido. Augusto cursa o $7^{\circ}$ ano do ensino fundamental, tendo sido reprovado por três vezes, e apresenta dificuldade para ler. Sobre o abuso sexual cometido, Augusto foi acusado em agosto de 2011. Confirmou que, em dezembro de 2010, quando estava com 16 anos, levou o menino (de 8 anos), vizinho próximo de sua casa, para debaixo de uma árvore e colocou seu pênis na boca da criança. Augusto diz ter sido muito ruim o ato sexual, pois não sentiu prazer.

Daniel (14 anos) é o primeiro de um casal de filhos. Sua mãe, natural do Ceará, quando jovem mudou-se para São Paulo onde conheceu o pai de Daniel. Casaram-se e tiveram dois filhos. Quando Daniel tinha 4 anos e sua irmã 6 meses de vida, sua mãe não aguentou mais a violência física e psicológica praticada pelo marido. Mudaram-se para Goiânia, onde vivem há 10 anos. A mãe trabalha como doméstica. Há um ano, a irmã de Daniel foi morar com a família no Ceará, devido a dificuldades financeiras. A relação de Daniel com sua mãe é de controle e submissão, ele aceita tudo o que ela ordena. Na escola, Daniel escreve e lê com lentidão. Já foi reprovado no $5^{\circ}$ ano por três vezes. Após o ato cometido, sua mãe decidiu retirá-lo da escola até "tudo se resolver". Desde então fica em casa sozinho assistindo desenhos na televisão. Sobre o abuso sexual cometido por Daniel, o menino (vítima) relatou na delegacia que quando tinha 9 anos, Daniel pediu pela primeira vez que tirasse a roupa e se sentasse no seu colo, ocasião em que introduziu o pênis em seu ânus. Daniel confirmou toda a acusação e afirmou que parou de fazer isso por causa da denúncia, pois estava "viciado" nessa "brincadeira", perpetrada durante um ano.

\section{Instrumentos}

O instrumento utilizado de orientação qualitativa, que permitiu a expressão do sujeito no contexto clínico foi a entrevista clínica. Turato (2003) defende que a entrevista clínica é um instrumento propício à pesquisa clínicoqualitativa. Nessa perspectiva, a entrevista é compreendida como um encontro interpessoal, no qual se estabelece um setting em que se valorizam o vínculo e a reflexão de ideias, opiniões, valores e atitudes. A entrevista clínica semidirigida é composta de questões abertas. Esta é a proposta mais indicada para a pesquisa clínica qualitativa, pois há a valorização da relação entre pesquisador e participante.

\section{Procedimentos}

Diante do contrato terapêutico e de pesquisa, os atendimentos se iniciaram no final do mês de março de 2012 e seguiram até final do mês de outubro de 2012. Todos os atendimentos foram gravados com gravador de áudio digital, tiveram duração de 60 minutos, e frequência semanal junto ao adolescente e mensal junto à família. Foi realizada uma média de 12 atendimentos individuais e cinco atendimentos familiares.

\section{Cuidados Éticos}

A pesquisa foi inscrita no Comitê de Ética em Pesquisa do Instituto de Ciências Humanas - IH, da Universidade de Brasília - UnB, sendo aprovado em dezembro de 2011, com o aparecer $\mathrm{n}^{\circ}$ 08-10/2011. O Termo de Consentimento Livre e Esclarecido (TCLE) seguiu as diretrizes e normas regulamentadoras de pesquisas envolvendo seres humanos, do Conselho Nacional de Saúde, Resolução n ${ }^{\circ} 196$ de 10 de Outubro de 1996 e do Conselho Federal de Psicologia, Resolução CFP ñ 016/2000 de 20 de Dezembro de 2000.

\section{Construção e análise das informações}

Para a análise e interpretação das informações produzidas foi utilizado apenas o registro do primeiro atendimento, como expressão inicial dos adolescentes no 
contexto clínico, referente ao abuso sexual cometido. As informações foram gravadas e transcritas para análise, tendo como referencial o método construtivo-interpretativo. Esse método de análise está fundamentado na Epistemologia Qualitativa proposta por González Rey (2005a, 2005c).

De acordo com a Epistemologia Qualitativa de González Rey (2005a, 2005c), o lugar do dado é substituído pelo indicador. $\mathrm{O}$ dado é percebido como uma entidade estática, e o indicador como um elemento vivo, que se integra às manifestações do estudo pelos processos de interpretação e construção teórica do pesquisador. Os indicadores são apreendidos nas expressões verbais e não verbais do sujeito. A partir dos indicadores são configurados núcleos de sentidos subjetivos, os quais constituirão a produção teórica acerca do tema em estudo. Com base nessas considerações, serão apresentados dois núcleos de sentidos e seus desdobramentos, que foram construídos a partir dos indicadores presentes no primeiro atendimento clínico aos dois adolescentes que cometeram abuso sexual contra crianças.

\section{Resultados e Discussão}

A expressão dos adolescentes logo no primeiro atendimento clínico aponta para produções subjetivas referentes à violência cometida, emoções anteriores ao abuso sexual e emoções geradas após a denúncia, além dos demais desdobramentos sociais. Portanto, serão apresentados dois núcleos de sentidos subjetivos referentes ao abuso sexual cometido, os quais serão exemplificados com trechos da entrevista clínica de ambos participantes.

\section{Abuso Sexual - "Uma Experiência Inusitada"}

Ao se expressarem durante o primeiro atendimento clínico sobre o abuso sexual cometido, tanto Augusto quanto Daniel demonstram uma expectativa a respeito do ato sexual, com um sentido de experimentação, de curiosidade.

Pesquisadora: Mas isso foi ideia sua ou você ficou... Sabia dessas coisas e quis?

Augusto: Foi, foi quase isso né, só que de uma forma inesperada.

Pesquisadora: Em algum momento você percebia que tinha alguma atração, achar legal...

Augusto: É... Pensar alguma coisa e aconteceu outra, como aconteceu... Já era tarde demais.

Pesquisadora: Você queria também?

Daniel: É pra quando chegasse essa hora verdadeira, não fizesse nada de errado, quando chegasse a hora verdadeira, quando tivesse a mulher, não fizesse nada de errado.
Pesquisadora: Você falou de um filme pornô. Você tinha assistido antes?

Daniel: Assistimos, eu e ele [vítima], mas só a primeira parte.

Peres (2012) afirma que, "embora o sujeito produza uma subjetividade que aparece em um momento de sua própria história, ela não pode ser descolada da história da sociedade em que vive" (p. 194). Nesse aspecto histórico e social da sexualidade, cada vez mais a sociedade idealiza e reproduz uma sexualidade hedonista e performática, com padrões distantes do aspecto relacional que a constitui. A sociedade brasileira tem utilizado a prática de exibição dos corpos por meio de mecanismos culturais veiculados principalmente pela mídia, e essa prática tem alcançado crianças e adolescentes (Felipe, 2006). Quanto aos adolescentes que cometeram abuso sexual, tanto para Daniel quanto para Augusto, a relação com a televisão é sua principal via de contato social e lazer, sendo esse o meio que mais veicula informações relacionadas à sexualidade a que esses adolescentes estão expostos.

A outra via relacional desses adolescentes é a família, com relações dominadoras, especialmente em relação às mães. Por sua vez, as mães assumem uma relação submissa com a religião, e transferem tal controle religioso aos filhos, por meio da repressão da sexualidade. Os adolescentes, assim, se deparam com informações contraditórias quanto à sexualidade, são estimulados pela mídia, filmes e novelas; e vivem a repressão da família e da religião, o que gera conflito subjetivo. Há também as relações que se constituem no grupo de futebol da rua que Augusto começou a participar e compartilhar das "brincadeiras" que aconteciam com a criança (vítima) e outros meninos; ou quando Daniel e seu colega, uma criança mais nova, assistiam parte de um filme pornográfico. Os dois contextos podem ter gerado curiosidade e legitimado nos adolescentes a crença da aceitação de uma experiência de dominação.

Ao vivenciar crenças religiosas rígidas, o contexto familiar e religioso de ambos os adolescentes que cometeram abuso sexual contribuem para uma subjetividade social proibitiva. Seja quanto a falar sobre sexo com seus filhos, ou sobre namorarem, o que indica uma educação repressora e não dialógica. Padrões de relações pautados por violência, instabilidade afetiva e desorganização, tanto na família como no grupo social, são indicativos de reincidência de abuso sexual cometido por adolescentes. Daí a importância desses fatores serem observados e acompanhados (Forensic Psychology Practice, 2006).

Assim, a educação repressora quanto à sexualidade também pode ser considerada um aspecto subjetivo que constitui o sentido de curiosidade e experimentação do abuso sexual. Portanto, para os adolescentes a transgressão 
pode representar a possibilidade de vivenciar sua sexualidade reprimida. Nesse sentido, Oliver (2007) aponta para aspectos preventivos do abuso sexual de crianças e/ ou adolescentes por adolescentes. Dentre eles, destaca a importância de conversar com os jovens sobre os danos e as causas do abuso sexual; de se conhecerem, conhecerem seus desejos e necessidades e refletirem sobre suas possibilidades reais, propiciando-lhes uma educação sexual saudável. Essa indicação preventiva requer uma comunicação aberta e dinâmica, entre jovens e adultos. Entretanto, o diálogo acolhedor só é possível quando há a construção de uma relação respeitosa e horizontal, principalmente entre pais e filhos.

Quanto à dificuldade de reflexão do adolescente que cometeu abuso sexual, fica evidente, no caso de Augusto sua ação na prática do abuso sexual como impulsiva e não reflexiva (Chagnon, 2008; Marcelli \& Braconnier, 1989). Essa falta de reflexão é percebida nas verbalizações pouco elaboradas do adolescente, quando diz o que sentiu, mas com dificuldades para definir sua experiência.

Pesquisadora: Você pensou nas consequências?

Augusto: (silêncio) Foi assim, uma coisa inesperada, aí aconteceu foi totalmente ruim...

Pesquisadora: Inesperada?

Augusto: É... que aconteceu. Foi sem motivo, eu nem saía pra rua, ficava só dentro de casa.

Pesquisadora: Como aconteceu?

Augusto: Não durou assim... como tá no papel... Eles [oficiais de justiça na delegacia] falou que foi muito tempo, e que tava bom... Não chegou ao caso de sentir prazer, né?

Ao falar sobre o abuso sexual, Augusto repete as palavras - "inusitado", "de uma hora para a outra", "de forma inesperada" - e em outras vezes se silencia. Também demonstra certa surpresa quanto ao seu ato. Expressa frustração quanto às suas expectativas iniciais, pois não sentiu prazer, e "foi totalmente ruim". Peres (2012) afirma que é a complexa experiência emocional de contradições na vida concreta do sujeito que permite gerar sentidos subjetivos que orientam suas atividades e relações. Nessas expressões de Augusto, além da falta de reflexão, a contradição se faz presente. Ao mesmo tempo em que existe o desejo da experimentação do ato sexual, que é expresso de maneira sutil, é também considerado um ato ao acaso, como se jamais tivesse pensado na possibilidade, e em outro momento demonstra frustração a determinada expectativa.

$\mathrm{Na}$ experiência de Daniel, a contradição também se faz presente. Ele diz o que pensava sobre o abuso sexual, sobre seu desejo, porém não assume inteiramente a responsabilidade do seu ato, deposita parte da culpa na vítima. A consciência da culpa e ao mesmo tempo a necessidade em compartilhar essa culpa, são edificadas diante da gravidade da experiência do abuso sexual, pois o abuso foi perpetrado durante um ano. Daniel afirma que perguntava para a vítima se queria parar e esta dizia que não, o que para ele o autorizava na continuidade do seu ato, e diminuía a culpa e responsabilidade.

Daniel: A verdade é que o F. [vítima] quis, eu vivia perguntando pra ele se ele queria parar, ele dizia que não, aí deu no que deu... eu não ia fazer nada sem ele querer...

Pesquisadora: Você queria?

Daniel: Pouquinho.

A tentativa de diminuir a culpa ou tentar justificar o acontecido expressa um sentido subjetivo de reparação do sofrimento posterior, discutido no próximo núcleo de análise. Tanto Daniel quanto Augusto, afirmam que sabiam que o que fizeram era errado, porém não sabiam das consequências e de se tratar de um crime. Tais afirmações remetem a um aspecto social recorrente em contextos sociais vulneráveis, uma educação formal e preventiva falha.

\section{Abuso Sexual - "Se Arrependimento Matasse..."}

No primeiro atendimento, tanto Augusto quanto Daniel expressaram emoções que refletem sentidos subjetivos gerados após cometerem o abuso sexual, ao retornarem ao contexto social (discriminação social, decepção da família, ameaça da família da vítima) e também ao vivenciarem o contexto da justiça (denúncia, audiências, iminência da internação, decisão da medida socioeducativa). São emoções que expressam um sofrimento subjetivo posterior, denominado por eles como "dor" e "angústia". Uma primeira emoção expressa pelos adolescentes é o medo. Medo das ameaças da mãe da vítima, medo da medida de internação socioeducativa, de ser considerado bandido, de sofrer discriminações e de não saber o dia de amanhã em suas vidas. O medo gera um sentido subjetivo de insegurança.

Augusto: É. Ele (policial) chegava na parte, falava assim em voz alta, aí ele falava: "você fez?", eu falei: "não, só aquela primeira parte que o senhor falou, mais nada". Falou assim que podia ser julgado no cartório ou alguma coisa assim, o abuso sexual a pessoa pode pegar de 1 a 8 anos de prisão, aí eu comecei a chorar [começa a chorar].

Pesquisadora: Sua mãe tá com medo de acontecer o que? Daniel: Ela tá com medo de, de acontecer alguma coisa [gaguejou]... ela [mãe da vítima] vivia falando pras pessoas que ia fazer mal pra mim. 
Segundo Santos (2003) o medo é um componente básico da experiência humana relacionado ao senso de sobrevivência e proteção. Entretanto, uma reação de fuga, de negação e precaução é também uma emoção que na contemporaneidade tem se configurado como um mal-estar social, gerado pela cultura da violência. Tal cultura se constitui numa sociedade capitalista, desigual e excludente. Nesse cenário, o medo embora seja uma emoção singularizada, é socialmente constituída. Na experiência de Augusto e Daniel, o medo configura-se na iminência de não terem um futuro, de sofrerem retaliação social, diante do estigma construído socialmente ao cometer o ato de violência sexual.

O medo comparece diante da ameaça da mãe da vítima, do afastamento e críticas da vizinhança ou da inadequação da forma em que se realiza a investigação na delegacia. Esses atos em si não geram responsabilização, apenas intimidação ao adolescente. Ao cometerem o abuso sexual, é prioritária sua responsabilização, porém o ato cometido não os retira da condição de sujeitos de direito e em condição peculiar de desenvolvimento. Esse é um dos aspectos que novamente evidencia a complexidade do abuso sexual enquanto uma manifestação da violência sexual. A contradição é expressa na condição de vítima e perpetrador: o adolescente é vítima de um sistema social excludente e cometeu abuso sexual contra criança. Diante dessa realidade, o Estado, a Justiça, a família e a sociedade precisam enfrentar o desafio duplo de protegê-los e responsabilizá-los.

Augusto: Aí começou a dar o choque né em mim, tava nervosa [delegada]

Pesquisadora: O quê que ela [delegada] falava?

Augusto: Ah, ela falava assim que... eu falava a minha versão, sabe? E ela falando tipo assim: "É mentira", foi bem ruim.

Pesquisadora: $\mathrm{O}$ que você acha... como que vai ser essa conversa amanhã [diante da juíza]?

Daniel: Vai ser uma conversa pacífica, mas tenho medo de esquecer tudo o que eu disse.

Pesquisadora: Medo de esquecer tudo na hora?

Daniel: Hamham, sobre pressão a gente esquece tudo mais rápido.

A responsabilização do adolescente por meio da medida socioeducativa não significa que seus outros direitos não devam ser garantidos, pois se trata de um "um jovem que por acaso é um infrator, e não de um infrator que por acaso é um jovem" (Conceição, 2010, p. 95). Na delegacia, a pressão emocional, agressividade verbal feita sobre os adolescentes pode colocá-los não apenas na condição de acusado, mas levá-los a vivenciar uma "estigmatização", uma discriminação contínua ao longo de sua experiência com a justiça. No entanto, autores referência no tema da ofensa sexual cometida por adolescentes (Marshall, 2001) são de opinião unânime de que o adolescente precisa ser responsabilizado.

No caso de Daniel, no âmbito social e familiar, a principal consequência vivenciada por ele foi o isolamento social e consequente solidão. A mãe de Daniel, após a denúncia e sofrerem ameaças da mãe da vítima, decidiu retirar Daniel da escola e esperar "tudo se resolver" com a justiça. Assim, ela retirou do filho o único espaço de socialização com pares que tinha, além da igreja que frequenta com a mãe. Desde então, Daniel fica em casa durante todo o dia sozinho assistindo televisão, "trancado", se sente destituído de sua liberdade, de seu direito de estudar, brincar, correr, ter amigos. Assim, o abuso sexual cometido por ele e seus desdobramentos tornou-se um marco de mudança e sofrimento em sua vida. Passou a ter contato social apenas com sua mãe e algumas amigas dela.

Quanto às características parentais, Zankman e Bonomo (2004) relataram que alguns pais têm alto grau de negação, culpa, vergonha e raiva quanto ao comportamento agressivo do filho, em decorrência dos sentimentos de responsabilidade sobre este. Dentre essas emoções, a mãe de Daniel vivencia especialmente a vergonha. Ao sofrer ameaça da mãe da vítima e discriminação da vizinhança, ela imediatamente deixa o filho "preso" em sua própria casa.

Pesquisadora: Aí você tá ficando em casa sozinho todo dia?

Daniel: Sozinho, trancado, só assistindo TV, difícil de sair [voz infantil].

Pesquisadora: O que você acha dessa situação?

Daniel: Péssima.

Pesquisadora: Mas agora como você queria que estivesse esta situação?

Daniel: Que tivesse tudo bem, tudo na paz, assistindo TV, trabalhando, estudando...

González Rey (2004) diz da importância do outro na constituição do sujeito. $\mathrm{O}$ outro será significativo no desenvolvimento da pessoa somente ao se converter em fonte de produção de sentido subjetivo que está sempre associado à emocionalidade. Destaca-se, portanto, a relevância de Daniel de se relacionar socialmente e o quão preocupante é a atitude da mãe de retirar esse direito do filho, não negado nem mesmo pela justiça. Evidente que foi um ato desesperado da mãe em protegê-lo, porém esse pode ser um aspecto inibidor do desenvolvimento de Daniel. O isolamento social pode dificultar o reconhecimento do outro 
enquanto sujeito, aspecto relevante para que o adolescente não venha a cometer outros abusos sexuais assim como desenvolver relações saudáveis com outras crianças e adolescentes.

Seguindo essa reflexão, ao se relacionar principalmente com a sua mãe, afetivamente distante, e com a televisão, um objeto que expressa uma realidade fantasiosa por meio dos desenhos animados, Daniel começa a gerar novos sentidos, de negação e rejeição à adolescência e à vida adulta. $\mathrm{O}$ adolescente passa a rejeitar a realidade social na qual vive, permeada por violência e discriminação, passa a desejar viver a realidade que os desenhos lhe apresentam, sem limites e frustrações. A realidade de Daniel tem se tornado cada vez mais passível de sofrimento. Além do isolamento imposto pela mãe, ainda vivencia a discriminação social na vizinhança. Esse é outro fator que fortalece o isolamento de Daniel, pois brincar com qualquer outra criança na rua longe de adultos ou dentro de casa pode se tornar um precedente para a mãe da vítima cumprir sua ameaça de prejudicar ainda mais Daniel. Enfim, Daniel passa a viver um ciclo de isolamento social.

Daniel: A mãe dele [vítima] pode tá me espiando, inventando história só pra me encrencar.

Pesquisadora: Você não pode ter mais nenhum amigo?

Daniel: Pra num pensar nada demais.

O sentido subjetivo do sofrimento de Daniel diante do isolamento, posterior à prática do abuso sexual, é de solidão. Portanto, na perspectiva de Daniel a vítima não está em sofrimento, pois refere tê-lo visto brincando livremente pela rua, "fazendo pipa". Ou seja, a criança não estava isolada e solitária, aspectos que configuram sofrimento para o adolescente. Nesse sentido, ele não percebe seu ato como uma violência que gera sofrimento ao outro, apenas a si mesmo.

Pesquisadora: Como você acha que ele [vítima] tá nessa história?

Daniel: Não sei, mas ele ainda anda pela rua... tava sentado lá fora fazendo pipa, aí ele tava andando, ai fui direto pra dentro de casa.

Pesquisadora: Quê que você sente por ele hoje?

Daniel: Nada.

Aqui se pode perguntar: como ter percepção do sofrimento do outro, e do outro como sujeito, se ao longo de sua história, Daniel foi tão privado de "outros"? Daniel até então se desenvolveu em uma rede social e afetiva restrita, pois parte de sua infância conviveu pouco tempo com sua irmã. Por seu turno, seu pai foi uma referência ausente que quando presente desqualificava a mãe de Daniel com violência física e psicológica. Os demais familiares sempre viveram distantes e as poucas amizades são controladas pela mãe. Como o solitário poderá compreender o outro? Peres (2012), ao discutir a afetividade a partir da perspectiva histórico cultural da subjetividade de González Rey, afirma que "é o envolvimento afetivo e social recíproco que permite as pessoas se experimentarem mutuamente" (Peres, 2012, p. 188), ou seja, se perceberem enquanto sujeitos. Portanto, para perceber o sofrimento do outro, construir um sentido de empatia em relação ao outro, é preciso ser e estar com o outro. Assim, manter Daniel isolado favorece em que sua produção subjetiva continue limitada à condição de dominação e submissão experienciada na relação com a mãe.

Já para Augusto, no âmbito social e familiar, seu sofrimento está diretamente relacionado à decepção moral dos pais em relação a ele. $\mathrm{O}$ adolescente gerou um sentido subjetivo de vergonha e arrependimento pela decepção sentida pelos pais, desejando até mesmo fugir de casa para aliviar tal sofrimento. Entende todo esse processo como um "preço alto" a pagar. Essa experiência posterior de sofrimento gera arrependimento e culpa em Augusto, e maior consciência da gravidade do ato cometido. Porém, semelhantemente a Daniel, Augusto não tem percepção do sofrimento da vítima e não se arrepende pelo mal causado ao outro. Logo, também para Augusto, o outro não assume um lugar de sujeito.

Pesquisadora: Lembrando do que aconteceu, como que você entende esse fato hoje?

Augusto: Que foi ruim, que tá sendo um preço pra mim pagar muito alto, arrependimento né? Igual aquele ditado: "se arrependimento matasse..."

Pesquisadora: Você se arrependeu?

Augusto: [choro] Depois que a minha mãe contou pro meu pai... Eu acho que ele sentiu tanto desgosto. Que eu falei pra ela que eu ia fugir de casa...

Daniel, diante do sofrimento vivido após o ato cometido por ele, se arrependeu pelo que fez com sua vida e não com a vida do outro. Assim como Augusto desejou fugir, Daniel deseja que tudo se acabe e deseja esquecer o que passou como forma de aliviar o sofrimento, denominado por ele de "angústia" e "dor no peito". É claro o sofrimento pessoal e familiar diante de tantos desdobramentos posteriores ao abuso cometido. Percebe-se nos adolescentes a constituição de um sujeito que sofre e que produz emoções diante de um ato de violência. Entretanto, não conseguem perceber o outro sujeito que sofre. 
Daniel: Só senti angústia

Pesquisadora: Como é que é essa angústia dentro de você? Daniel: Uma dor no peito.

Pesquisadora: Quê que você tem vontade de fazer com essa angústia?

Daniel: Vontade de arrancar e jogar fora, jogar fora e viver em paz.

Diferentes autores (Marshall et al., 2005; Ward, Gannon, \& Birgden, 2007; Worling et al., 2010) postulam o processo de intervenção terapêutica junto ao adolescente que cometeu abuso sexual. A intervenção deve se concentrar em questõeschave: o adolescente deve assumir a responsabilização pelo ato cometido; desenvolver planos de prevenção; aumentar a consciência do impacto sobre a vítima; aumentar as relações sociais; aumentar a comunicação familiar; conhecimento saudável de atitudes sexuais e prossociais; assim como favorecer o desenvolvimento da autonomia do adolescente. Muitos desses aspectos ficam evidentes nos casos discutidos, especialmente quanto ao aumento das relações sociais. Devem ser relações nas quais o outro seja fonte de produção de sentidos, assim como um conhecimento saudável de atitudes sexuais para seu desenvolvimento.

\section{Considerações Finais}

Faz-se necessário conhecer o adolescente que cometeu abuso sexual e sua subjetividade. Percebê-lo e acolhê-lo como sujeito em desenvolvimento, sujeito este de direitos e deveres. Nesta pesquisa, o abuso sexual praticado pelo adolescente se apresenta como um marco em suas vidas, de transformações e sofrimento, um limite entre o antes e o depois em sua história. Nessa dinâmica, percebemos como o social e o cultural constituem a subjetividade humana. Encontramos um sujeito que sofre, que em muitos aspectos está com seu desenvolvimento comprometido em função de tantas limitações sociais e afetivas.

Portanto, para que ele não venha a cometer novamente tal ato e consiga se desenvolver de maneira saudável, o outro precisa ser presente e atuante em sua vida, para que consiga gerar um sentido de empatia e assim percebê-lo também como sujeito que sofre. $\mathrm{O}$ outro a quem nos referíamos podem ser seus familiares, que venham a percebê-lo como sujeito que pensa, sofre, sonha e que faz escolhas. Podem ser também os operadores do sistema socioeducativo, ao acolhê-lo como um adolescente de direitos e deveres. Direito ao acolhimento, ao respeito sem discriminação. Ao ser reconhecido como sujeito, o adolescente se reconhecerá como sujeito de deveres, ao se responsabilizar pelos seus atos perante a justiça, a sociedade e perante o outro pelo qual causou sofrimento.
Muitas são as contradições que constituem a subjetividade desses adolescentes: curiosidade e repressão da sexualidade; experimentação do ato sexual e arrependimento; relação submissa à mãe dominadora; desejo e culpa. Há ainda aspectos que marcaram a experiência do abuso sexual: isolamento e estigmatização social, não percepção do sofrimento da vítima, empobrecimento reflexivo. Tanto as contradições quanto os aspectos marcantes na experiência dos adolescentes, configuram-se como indicadores de sentidos subjetivos produzidos pelos adolescentes, referente à suas motivações e sofrimento diante da violência cometida. Portanto, o abuso sexual praticado se configura como um marco que limita direta ou indiretamente o desenvolvimento psíquico dos adolescentes. Seja por dimensões subjetivas individuais ou sociais, anteriores ou posteriores à violência.

Assim, os atendimentos posteriores devem se constituir enquanto um espaço que favoreça ao adolescente a produção de novos sentidos subjetivos referentes à sua experiência. Novos sentidos em relação à sua sexualidade, à violência praticada e sua responsabilização. Assim como novos sentidos referentes à relação de submissão e dominação na família, à importância dos pares no seu desenvolvimento, na perspectiva de ampliar sua rede social e sua capacidade reflexiva. Abrir novas possibilidades de produção subjetiva é imprescindível para o desenvolvimento e constituição destes adolescentes, enquanto sujeitos do seu pensamento, das suas emoções, e da própria história de maneira responsiva e reflexiva.

Os desafios encontrados ao longo da pesquisa se apresentam no âmbito teórico e prático. O desafio teórico refere-se à produção existente sobre ao tema, em sua maioria internacional, não alcança a complexidade da violência sexual praticada na adolescência, especialmente no contexto brasileiro. Paralelamente, um desafio prático, pois lidamos com adolescentes que vivem contextos sociais vulneráveis e dependem da sociedade, do Estado e da Justiça para serem sujeitos de direitos e deveres. Neste artigo enfatizamos, portanto, o compromisso social e ético da psicologia, diante dessa realidade complexa e contraditória.

\section{Referências}

Azevedo, M. A., \& Guerra, V. N. A. (1989). Crianças vitimizadas: A sindrome do pequeno poder (2a ed.). São Paulo: Iglu.

Bianchini, F., \& De Antoni, C. (2012). Adolescentes que abusam sexualmente de crianças e de outros adolescentes. In L. F. Habigzang \& S. H. Koller (Eds.), Violência contra crianças e adolescentes (pp. 123133). Porto Alegre, RS: Artmed. 
Brasil. (1990). Estatuto da Criança e do Adolescente: Lei $\mathrm{N}^{o}$ 8.069, de 13 de Julho de 1990. Recuperado de http:// www.planalto.gov.br/ccivil_03/leis/18069.htm

Chagnon, J. Y. (2008). As agressões sexuais: Uma organização de transtornos narcísico-identitários. Paidéia, 18(41), 495-515.

Chagnon, J. Y. (2009). A agressão sexual na adolescência: Um destino da hiperatividade. Ágora, 13(2), 275-290.

Conceição, M. I. G. (2010). A clínica do adolescente em meio fechado: Olhares sobre o contexto. In M. M. Marra, \& L. F. Costa (Eds.), Temas da clínica do adolescente e da família (pp. 87-103). São Paulo: Ágora.

Costa, L. F., Junqueira, E. L., Ribeiro, A., \& Meneses, F. F. F. (2011). Ministério da obrigação adverte: É preciso proteger os adolescentes ofensores sexuais. Avances en Psicología Latino Americana, 29(1), 33-46.

Costa, L. F., Junqueira, E. L., Meneses, F. F. F., \& Stroher, L. M. (2013). As relações familiares do adolescente ofensor sexual. Psico USF, 18(1), 33-44.

Costa, L. F., Junqueira, E. L., Meneses, F. F. F., Stroher, L. M. C., \& Moura, M. G. (2012). Construindo conhecimento sobre o adolescente que cometeu ofensa sexual. Contextos Clínicos, 5(2), 112-120.

Faleiros, V. P., \& Faleiros, E. T. (2007). Escola que protege: Enfrentando a violência contra crianças e adolescentes. Brasília, DF: Ministério da Educação.

Forensic Psychology Practrice. (2006). Adolescent sex offenders: A practitioner's portfolio. Boldemere, UK: The Willow Clinic.

González Rey, F. (2004). O sujeito, a subjetividade e o outro na dialética complexa do desenvolvimento humano. In L. M. Simão \& A. M. Martinez (Eds.), O outro no desenvolvimento humano (pp. 1-27). São Paulo: Thompson.

González Rey, F. (2005a). Pesquisa qualitativa em psicologia: Caminhos e desafios (Trad. M. A. F. Silva, Trad.). São Paulo: Pioneira Thomson Learning.

González Rey, F. (2005b). Sujeito e subjetividade: Uma aproximação histórico-cultural. São Paulo: Pioneira Thomson Learning.

González Rey, F. (2005c). Pesquisa qualitativa e subjetividade: Os processos de construção da informação. São Paulo: Pioneira Thomson Learning.

Machado, M. T. (2003). A proteção constitucional de crianças e adolescentes e dos direitos humanos. Barueri, SP: Manole.
Marcelli, D., \& Braconnier, A. (1989). Manual de psicopatologia do adolescente. Porto Alegre, RS: Artes Médicas.

Marshall, W. L. (2001). Agresores sexuales. Barcelona, España: Ariel.

Marshall, W. L., Ward, T., Mann, R. E., Moulden, H., Fernandez Y. M., Serran, G., \& Marshall, L. E. (2005). Working positively with sexual offenders: Maximizing the effectiveness of treatment. Journal of Interpersonal Violence, 20, 1096-1114.

Oliver, B. E. (2007). Three steps to reducing child molestation by adolescents. Child Abuse \& Neglect, 31, 683-689.

Ozella, S. (2002). Adolescência: Uma perspectiva crítica. In S. H. Koller (Ed.), Adolescência e psicologia: Concepções, práticas e reflexões críticas (pp. 16-24). Rio de Janeiro: Conselho Federal de Psicologia.

Ozella, S. (2003). Adolescências construidas: A visão da psicologia sócio-histórica. São Paulo: Cortez.

Penso, M. A., Conceição, M. I. G., Costa, L. F., \& Carreteiro, T. C. O. (2012). Jovens pedem socorro: $O$ adolescente que praticou ato infracional e o adolescente que cometeu ofensa sexual. Brasília, DF: Líber Livro e Universo.

Peres, V. L. A. (2012). O desenvolvimento da afetividade no cenário social familiar. Estudos Contemporâneos da Subjetividade, 2(2), 186-199.

Sanderson, C. (2005). Abuso sexual em crianças. São Paulo: Books do Brasil.

Santos, L. O. (2003). O medo contemporâneo: abordando suas diferentes dimensões. Psicologia: Ciência e Profissão, 23(2), 48-55.

Santos, B. R., Neumann, M., \& Ippolito, R. (2004). Guia escolar: Métodos para identificação de sinais de abuso e exploração sexual de crianças e adolescentes. Brasília, DF: Secretaria Especial dos Direitos Humanos e Ministério da Educação.

Turato, E. R. (2003). Tratado da metodologia da pesquisa clínico-qualitativa. Petrópolis, RJ: Vozes.

Vygotsky, L. S. (2005). Pensamento e linguagem. São Paulo: Martins Fontes.

Ward, T., Gannon, A., \& Birgden, A. (2007). Human rights and treatment of sex offenders. Sex Abuse, Springer Science, Business Media, 19, 195-216.

Worling, J. R., Litteljohn, M. A., \& Bookalam, D. (2010). 20 year prospective follow-up study of specialized 
treatment for adolescents who offended sexually. Behavioral Sciences and the Law, 28, 46-57.

Zankman, S., \& Bonomo, J. (2004).Working with parents to reduce juvenile sex offender recidivism. Journal of Child Sexual Abuse, 13(3/4), 139-156.

\section{Endereço para correspondência:}

Florença Ávila de Oliveira Costa

Endereço residencial: Praça C170, Quadra 397, Lote 11, Jardim América. Goiânia. CEP: 74.250-250

E-mail: florenca.avila@yahoo.com.br

\section{Endereço para correspondência:}

Liana Fortunato Costa

Endereço: SQN 104 blco D apto 307, Brasília-DF, CEP

70.733-040

E-mail: lianaf@terra.com.br

\section{Endereço para correspondência:}

Maria Inês Gandolfo Conceição

Endereço: SQS 212 blco B apt. 206, Brasília-DF, CEP

$70.275-020$

E-mail: inesgand@unb.br 